\title{
MAPPING BATHYMETRY BY LANDSAT DATA IN SHALLOW COASTAL ENVIRONMENT (CASE STUDY: THE SOUTHEAST OF THE CASPIAN SEA)
}

\author{
L. Amini ${ }^{1}$, Ataollah Abdollahi Kakroodi*
}

1- Dept. of Remote Sensing \& GIS, University of Tehran, Tehran, Iran, (1.amini, a.a.kakroodi)@ut.ac.ir

KEY WORDS: Bathymetry, Caspian Sea, Gomishan Lagoon, Landsat.

\begin{abstract}
:
Compared to traditional methods, remote sensing (RS) technique is an efficient, fast, low-priced and effective solution in bathymetry. In this study, a linear equation was applied between field and reflectance data to achieve bathymetry map. Landsat-8 is characterized by additional visible band compared with previous Landsat bands on coastal zone application, therefore, we apply two regions of spectrum to compare the accuracy of bathymetry, Bands 1, 3, 4 and bands 2, 3 and 4 respectively. Furthermore, Logarithmic transformation also applied on both spectral regions to have bathymetry map. The coefficient obtained from reflectance and filed data was applied on Tm bands to retrieve the bathymetry of Gomishan lagoon in 2000. The results show that the second spectral region, Bands 2, 3 and 4, is highly correlated with filed data and more accurate $\left(\mathrm{R}^{2}=0.94\right.$, $\left.\mathrm{RMSE}=0.35\right)$. Moreover, there is a relatively high accuracy between the retrieval of Gomishan bathymetry and the report of recent studies.
\end{abstract}

\section{INTRODUCTION}

Bathymetry using RS technique is a noticeable topic in coastal monitoring and research, especially climate change impact assessments on coasts (Ranasinghe, 2016). Bathymetric mapping of shallow waters has a great importance for coastal engineering and coastal science application as well as shipping safety (Leu and Chang, 2005; Grilli, 1998). Bathymetry methods divided to three groups, physical-based approach based on hyperspectral RS, empirical models based on multispectral RS and photogrammetric technique based on satellite stereo pair, which has a similar accuracy to the current satellite bathymetry derivation approaches (Hodúl et al., 2018). Empirical model, as an easy and practical method, requires only a limited number of in situ measurements at certain sampling spots to build a relation between bathymetry and image properties (Gao, 2009). Several algorithms have been proposed for bathymetry estimation using optical RS by utilizing either analytical or empirical methods. Benny and Dawson (1983), Spitzer and Driks (1986), and Philpot (1989) developed analytical model. Benny and Dawson (1983) developed a bathymetry inversion algorithm by incorporating the solar elevation angle correction. Spitzer approach (1986) is a analytical method, and it required the input of the spectral signatures of suspended and dissolved materials, and bottom reflectance. Philpot (1989) discussed the possible means to extend the inversion algorithm to more complex scenes where both bottom types (reflectance) and water quality. The most popular empirical method which was proposed by Lyzenga $(1981 ; 1985)$ assumes that the bottom reflected reflectance is a linear function of the bottom reflectance and an exponential function of the water depth. Ceyhun and Yalçin, as well as, (2010) Gholamalifard et al. (2013), tested multilayer perceptron among examining methods for bathymetry. Following Lyzenga method, Pacheco et al (2015) derived bathymetry using Landsat 8 imagery and LiDar data. Machine Learning (ML) approaches is another accurate method of bathymetry that some researchers have been recently utilized. Liu et al. (2015) investigated the potential of two artificial neural network models, MLP and general regression neural network for bathymetry estimation by utilizing IKONOS and Landsat imageries for their case studies. The aim of this study is the examination of the accuracy of coastal blue and blue bands in bathymetry by the following Lizang's (1985) algorithm. By building a linear relationship between field data and the reflectance of bands 1, 3, 4 and bands 2, 3, 4 the bathymetry was obtained. In order to evaluation this model, extracted coefficients by bands 2,3 and 4 from L8 and field data apply to TM to estimate Gomishan Lagoon depth located close to the study area (Figure 1).

\section{MATERIALS AND METHODS}

\subsection{Study Area}

The Caspian Sea as largest lake in the world is located between Europe and Asia. Its current level is about $27 \mathrm{~m}$ below the free water level, and almost without tides (Kakroodi et al., 2015). The southeastern of Caspian Sea is the case study (Figure 1). According to field data that collected on August 2016, its depth variation are about 0.63 to $6.66 \mathrm{~m}$.

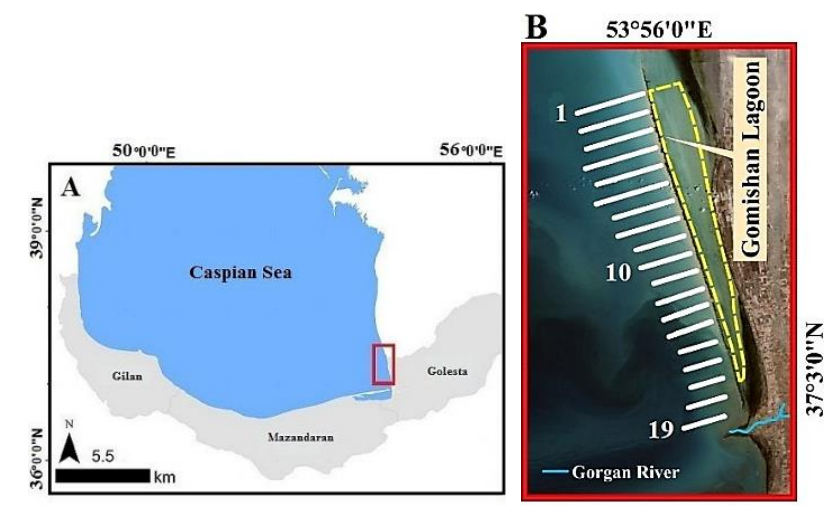

Figure 1. Figure 1. The location of the Caspian Sea (A); study area and depth transects shown in white line (B). 


\subsection{Remote Sensing in Water Bodies}

The attenuation of light in water is a relationship of increasing depth and wavelength. Attenuation intensity varies from electromagnetic spectrum in different wavelengths.

In the visible region, the red wavelength attenuates faster than the blue wavelength (Edwards, 1999). By plotting reflectance values versus depth $(<7 \mathrm{~m}$, except red band, linear and exponential trend line match to each other perfectly. Thus to examine the relationship between depth $(<7 \mathrm{~m})$ and reflectance is linear or exponential, depth estimated in two circumstance with logarithmic transformation and without logarithmic transformation.

\subsection{Pre-processing of Data}

To estimate depth, it is necessary to perform preprocessing on data. The result of recent researches has proved the accuracy of dark object subtract (DOS) atmospheric correction on Landsat- 8 imagery in coastal area (Nazeer et al., 2014). Therefore, we convert DN to reflectance and applied DOS algorithm. To provide subset from the study area is final step in image preprocessing. The field data coordinates also need to turn into image coordinates, WGS84 / UTM Zone 39. Then Field data divided to groups, training $(70 \%)$ and test $(30 \%)$ data. Interpolation also we applied on field data. The steps of bathymetry is shown in Figure 2.

\subsection{Bathymetry Estimation}

After preprocessing of data, the depth was estimated once by derived $a_{a}^{\prime} a_{i}^{\prime}, a_{j}^{\prime}=$ coefficients through multiple regression using training data and the corresponding reflectance 1, 3 and 4 bands with and without logarithmic transformation, and another time by $a_{0}, a_{i}, a_{j}=$ coefficients determined through multiple regression using training data and the corresponding reflectance 2, 3 and 4 bands with and without logarithmic transformation. For example, if suppose the relationship between depth and reflectance is linear, for 2, 3 and 4 bands the depth is estimated by:

$Z_{l g}=a_{\mathrm{D}}\left(X_{\mathrm{i}}\right)+a_{1}\left(X_{j}\right)+a_{2}\left(X_{\mathrm{k}}\right)$

$X_{i}, X_{j}, X_{\mathrm{k}}=$ the reflectance of blue, green and red bands, respectively that removed atmospheric effects.

If suppose the relationship between depth and reflectance is exponential, for 2, 3 and 4 bands depth is estimated by equation (1), but $X_{i}, X_{j}, X_{\mathrm{k}}$ are the logarithm of reflectance of blue, green and red bands, respectively that removed atmospheric effects.

\subsection{Evaluation of Model}

For assessing the overall performance of the estimated depth algorithm is computed RMSE:

$\operatorname{RMSE}\left(Z_{\text {Lsat }}, Z_{\text {echo }}\right)=\sqrt{\frac{\sum_{i=1}^{N}\left(Z_{\text {echo }}-Z_{\text {Lsatg }}\right)^{2}}{N}}$

$Z_{\text {gcko }}$ and $Z_{\text {isats }}$ are known depth obtained from the echosounder and estimated depth from the L8, respectively.

In addition to RMSE, we applied $a_{b}, a_{i}, a_{j}=$ coefficients determined through multiple regression using training data and

the corresponding reflectance 2, 3 and 4 bands from L8 to TM_2000 so that observe whether this model is enabled to retrieval Gomishan Lagoon depth in 2000 that is located near to the study area (Figure 1).

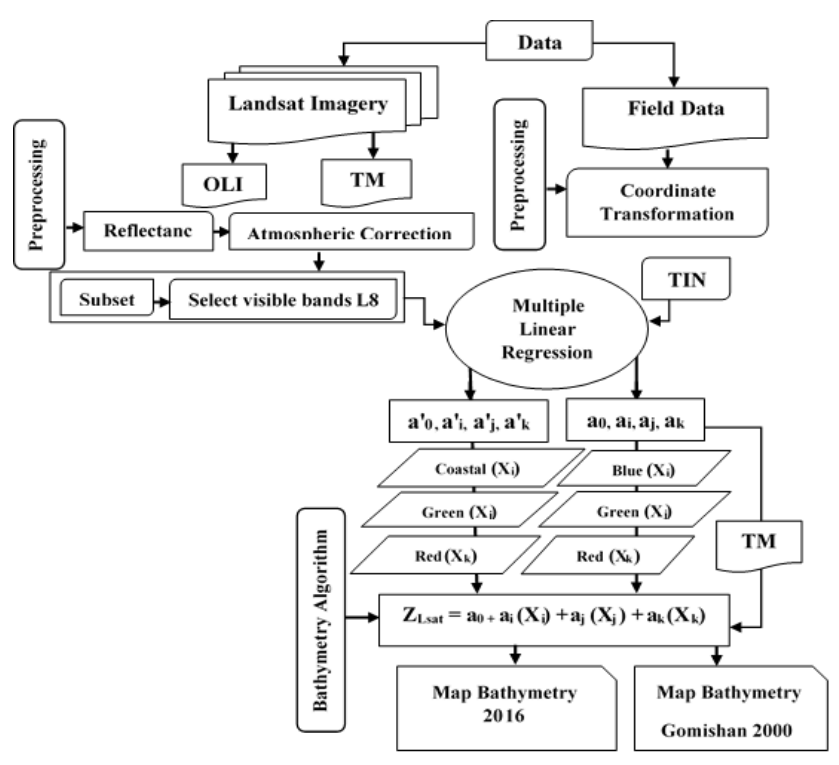

Figure 2. The steps of proposed methodology.

\section{RESULT}

\subsection{Retrieval the depth of Southeastern of Caspian Sea}

The depth was estimated based on linear algorithm (Lyzenga, $1978,1985)$ using the field data and the reflectance of bands 1 , 3,4 and also bands 2, 3 and 4 with and without logarithmic transformation. The difference depth maps (the difference of predicted depth from known depth) and their histograms in both linear and exponential conditions for bands 1,3,4 and bands 2, 3 and 4 is presented in Figures 3 to 6 separately.
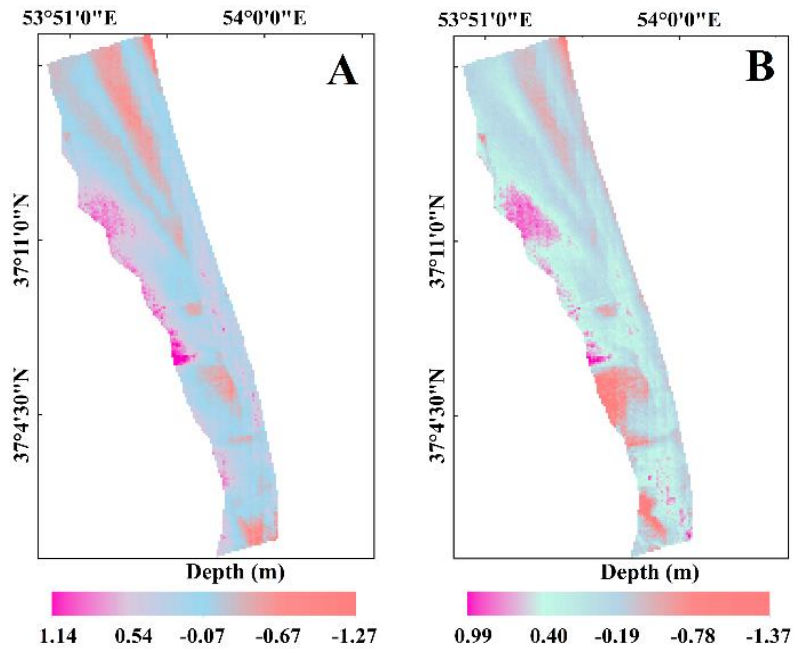

Figure 3. Two different maps (the difference of predicted depth from known depth) by bands 1, 3 and 4 without logarithmic transformation (A); with logarithmic transformation (B). 

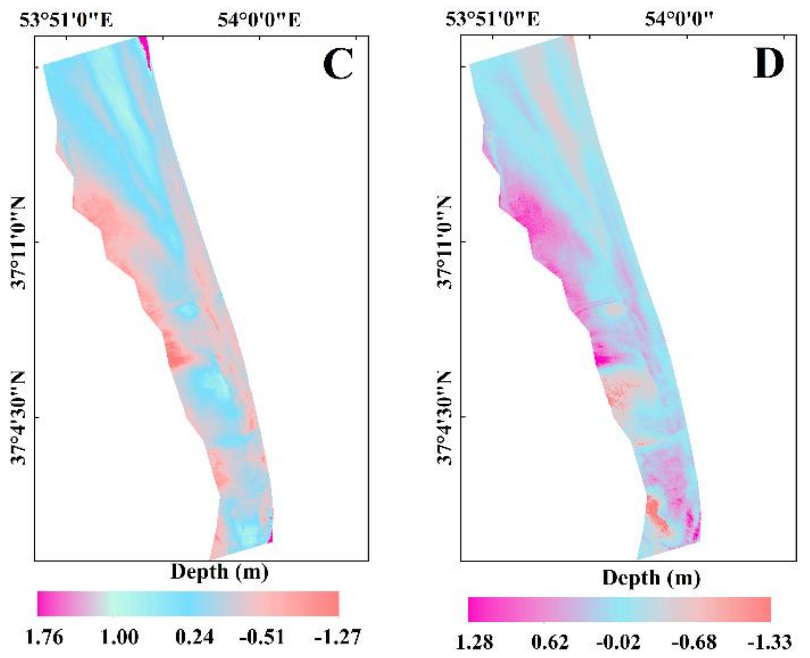

Figure 4. Two different maps (the difference of predicted depth from known depth) by bands 2, 3 and 4 without logarithmic transformation (C); with logarithmic transformation (D).
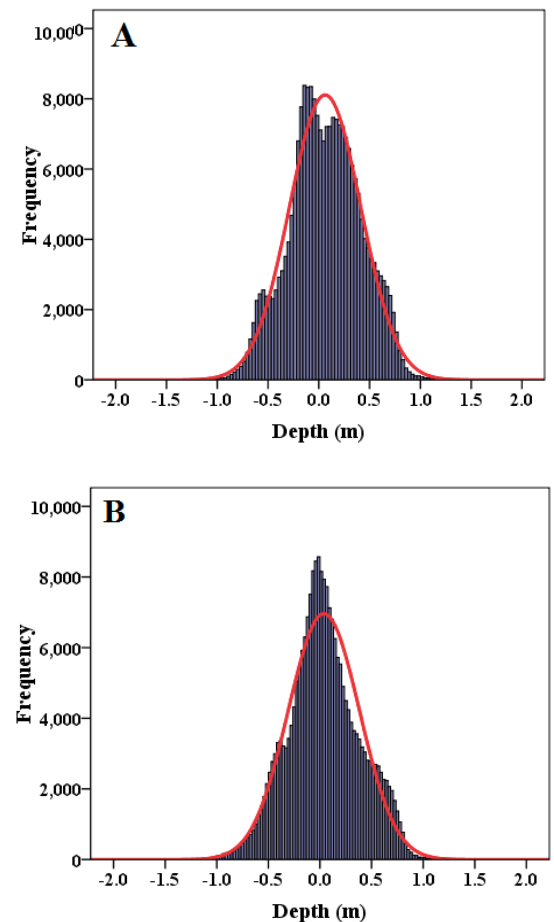

Figure. 5. Histogram of depth difference between known depth and bands 1, 3 and 4 in linear relation (A); Histogram of depth difference between known depth and the same bands in exponential relation (B). The red curve in both figures represent normal distribution.
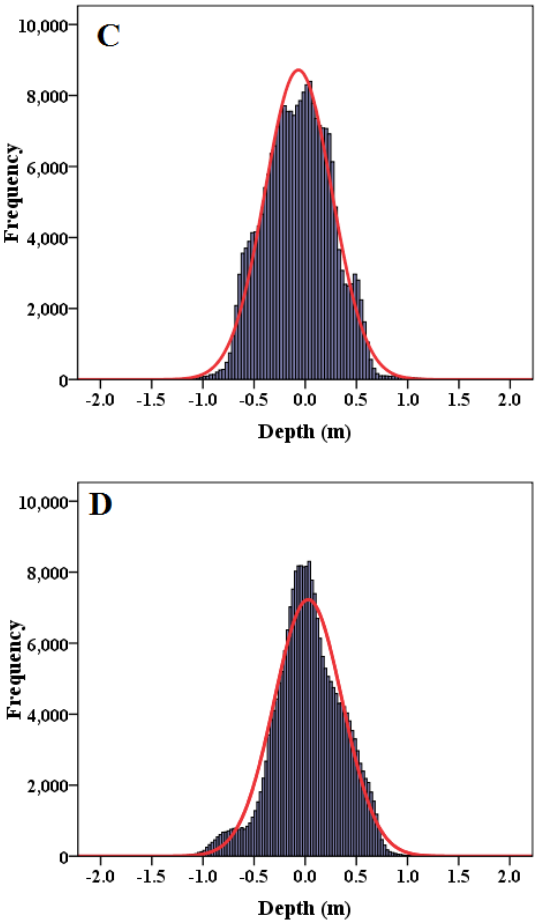

Figure 6. Histogram of depth difference between known depth and bands 2, 3 and 4 in linear relation (C); Histogram of depth difference between real depth and the same bands in exponential relation (D); the red curve in both figures represent normal distribution.

Figures 5 and 6 illustrate the histograms of difference maps by bands 2, 3, 4 and 1, 3, 4 respectively. There is a linear relationship between reflectance and depth $(<7 \mathrm{~m})$ and has a better result than the exponential relationship.

\subsection{Retrieval the depth of Gomishan Lagoon}

The average and the maximum depth of Gomishan is 1 and 2.5 meters respectively in 2000 (Scott, 1995: Kiabi et al., 1999). The bathymetric Gomishan map that estimated by coefficients determined through multiple regression using training data and the corresponding reflectance 2,3 and 4 bands from L8 (without logarithmic transformation) and its histogram are shown in Figures 7 and 8 respectively. 

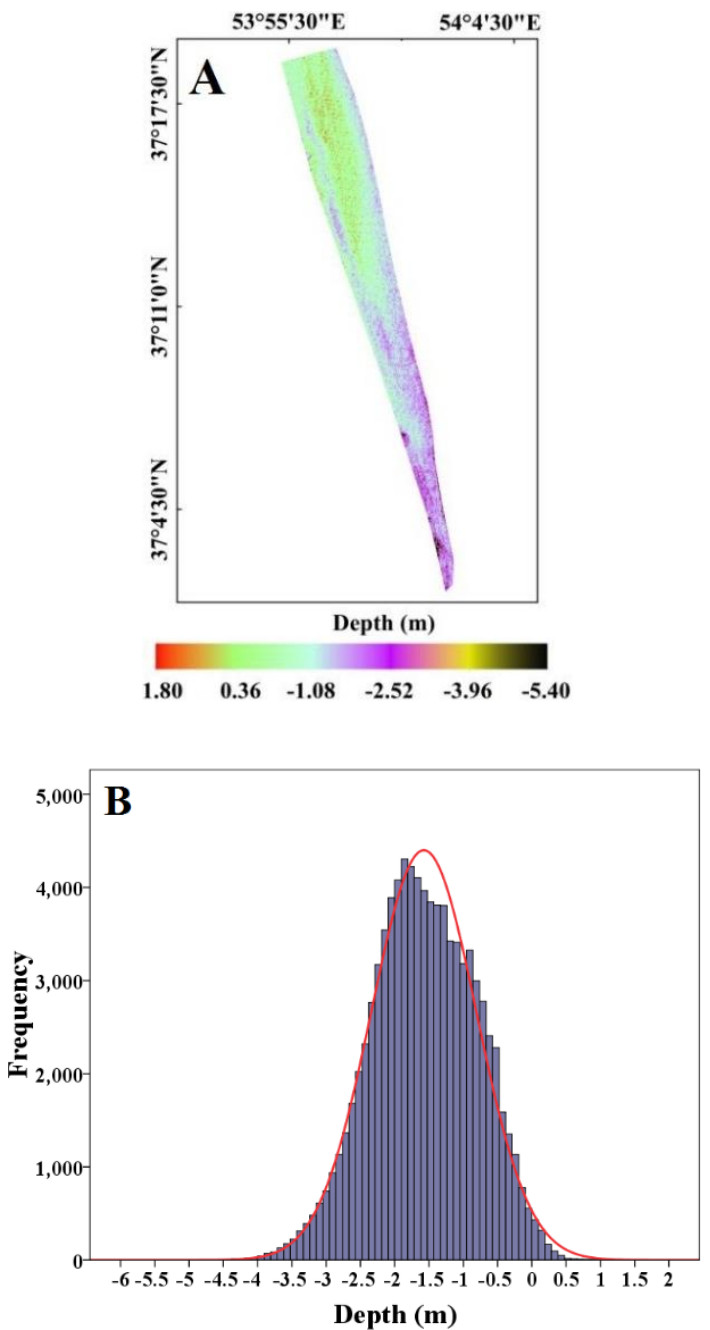

Figure 7. (A) Bathymetry Map of Gomishan Lagoon; (B) histogram of bathymetry map.

\section{CONCLUSION}

In this study, the depth was estimated using free and available Landsat- 8 imagery with medium spatial resolution. The accuracy of estimated depth from bands 2, 3 and 4 (in linear relation) is very high $\left(\mathrm{R}^{2}=0.94\right.$ and $\left.\mathrm{RMSE}=0.35\right)$. The highest and lowest accuracy belong to transect 17 and transect 19 respectively. Transect 19 which has the highest RMSE among other transects, this could be due to the proximity of this transect to the Gorgan River (Figure 1) The results show that the normal distribution diagram is more fitted to histogram of bands 2, 3 and 4 compared to histogram of bands 1, 3 and 4. Up to $7 \mathrm{~m}$ depth a linear relation has a better result than the exponential relation. According to what histograms show, up to a depth of 7 meter, the blue band is more accurate than the coastal blue band, although this difference is not significant.

Furthermore, the depth retrieval of Gomishan lagoon is nearly matched as reported in 2000. As the histogram indicates that the most frequencies belong to interval of 1 to $2.5 \mathrm{~m}$ and its average is $1.5 \mathrm{~m}$ that is matched to what reported by Scott and Kiabi (Scott, 1995: Kiabi et al., 1999).

The results confirm the ability of Landsat images to estimate depth in shallow coastal environment. In bathymetry by satellite, reflectance date is affected by various factors including water clarity, depth, and atmospheric conditions. These factors certainly impact on reflectance directly and have a negative effect on the accuracy of bathymetry. Hence, removing such an external factors result in more accurate and reliable barometric map. However, in spite of the limitations of depth estimation using satellite imagery, as mentioned above, these methods are still a quick and efficient way to estimate depth.

\section{ACKNOWLEDGMENT}

This work was supported by Iran National Science Foundation (INSF) under grant No 95849749.

\section{REFERENCES}

1. Benny, A.H., and Dawson, G.J., 1983. Satellite imagery as an aid to bathymetric charting in the Red Sea. The Cartographic Journal, 20 (1), 5-16.

2. Edwards, A., 1999. The Remote Sensing Handbook for Tropical Coastal Management, UNESCO: Paris, France.

3. Gao, J. 2009. Bathymetric Mapping by Means of Remote Sensing: Methods, Accuracy and Limitations. Progress in Physical Geography, 33, 103-116.

4. Gholamalifard M, Kutser T, Esmaili A, Abkar A, Naimi, B., 2013. Remotely sensed empirical modeling of bathymetry in the southeastern Caspian Sea. Remote Sens 5(6):27462762. doi: $10.3390 /$ rs5062746.

5. Grilli, S.T., 1998. Depth inversion in shallow water based on nonlinear properties of shoaling periodic waves. Coastal Engineering 35 (3), $185 \mathrm{e} 209$.

7. Hodul, M., Bird, S., Kundby, A., Chenier, R., 2018. Satellite derived photogrammetric bathymetry. ISPRS J.

Photogram. Remote Sensing 142, 268-27 http://dx.doi.org/10.1177/0309133309105657.

8. Kakroodi, A.A., Leroy S.A.G., Kroonenberg, S.B., Lahijani, H.A.K, Alimohammadian. H., Boomer, I., Goorabi. A., 2015. Late Pleistocene and Holocene sea-level change and coastal palaeoenvironment evolution along the Iranian Caspian shore. Marine Geology 361, 111-125.

9. Kiabi, H.B., Ghaemi, R.A., Abdoli, A., 1999. Wetland and Riverian Ecosystems of Golestan Province. Department of the Environment, Gorgan. 182pp (in Persian).

10. Leu, L., Chang, H., 2005. Remotely sensing in detecting the water depths and bed load of shallow waters and their changes. Ocean Engineering 32, 1174e1198.

11. Liu, S., Gao, Y., Zheng, W., Li, X., 2015. "Performance of Two Neural Network Models in Bathymetry." Remote Sensing Letters 6 (4): 321-330. doi:10.1080/2150704X.2015.1034885.

12. Lyzenga, D.R., 1978. Passive remote sensing techniques for mapping water depth and bottom features. Appl. Opt., 17, 379-383.

13. Lyzenga, D.R., 1985. Shallow-Water Bathymetry Using Combined Lidar and Passive Multispectral Scanner Data. International Journal of Remote Sensing, 6, 115-125. http://dx.doi.org/10.1364/AO.17.000379.

14. Nazeer, M., Nichols, J.E. \& Yung, Y., 2014. Evaluation of atmospheric correction models and Landsat surface reflectance product in an urban coastal environment. International Journal of Remote Sensing, 35(16), 62716291.

15. Ranasinghe, R., 2016. "Assessing Climate Change Impacts on Open Sandy Coasts: A Review." EarthScience Reviews 
The International Archives of the Photogrammetry, Remote Sensing and Spatial Information Sciences, Volume XLII-4/W18, 2019

GeoSpatial Conference 2019 - Joint Conferences of SMPR and GI Research, 12-14 October 2019, Karaj, Iran

160: $320-332$.

doi:10.1016/j.earscirev.2016.07.011.

16. Scott, D.A., 1995. A Directory of Wetlands in the Middle

East. IUCN, the World Conservation Union. 560pp.

17. Spitzer, D. and Dirks, R.W.J., 1986. Classification of Bottom Composition and Bathymetry of Shallow Waters by Passive Remote Sensing. Proceedings of the 7th ISPRS Commission VII Symposium on Remote Sensing for Resources Development and Environmental Management, 2, 775-777.

18. Pacheco, A., Horta, J., Loureiro, C., Ferreira, O., 2014. Retrinal of nearshore bathymetry from Landsat 8 images: A tool for coastal monitoring in shallow waters, Remote Sensing of Environment 159 (2015) 102- 116. 